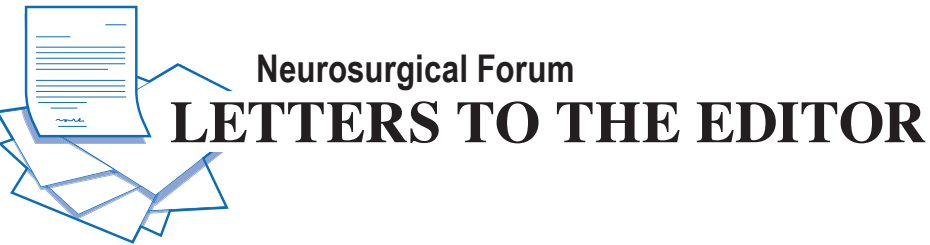

\section{Minimally invasive techniques: the new frontier in neurosurgery}

$\mathrm{T}$

1 O THE EDITOR: We have read with great attention the article by Park et al. ${ }^{8}$ (Park J, Son W, Kwak Y, et al: Pterional versus superciliary keyhole approach: direct comparison of approach-related complaints and satisfaction in the same patient. $J$ Neurosurg [epub ahead of print March 2, 2018. DOI: 10.3171/2017.8.JNS171167]). We would like to congratulate the authors. It is indeed a very interesting paper, and we agree with many of the authors' statements, e.g., the fact that both approaches are commonly used for cerebrovascular and skull base procedures. The authors analyzed data obtained from 21 patients during follow-up visits after surgery performed over an 11-year period. All patients included in the study had undergone an ipsilateral supraciliary keyhole approach and a contralateral pterional craniotomy for bilateral intracranial aneurysm surgery. Outcome measures included overall patient satisfaction as rated on a visual analog scale (VAS) and patient responses to a questionnaire covering 5 variables related to the surgical approaches: craniotomyrelated pain, sensory symptoms, cosmetic complaints, palpable cranial irregularities, and limited mouth opening. ${ }^{5}$ They concluded that a supraciliary keyhole approach provides a much higher level of patient satisfaction than a pterional approach, despite the facial scar., ${ }^{1,2}$

However, we also noticed some methodologic and analytical issues that we think are worth discussing.

First, to compare clinical, functional, and aesthetic results of 2 surgical techniques, we agree that prospective randomized studies would have more impact than analysis of data from patients who underwent bilateral craniotomies (with two different approaches in each patient). In addition, the authors did not mention the follow-up time..$^{2,3}$

Second, the long study period (11 years) may compromise data homogeneity, because the procedures could have been performed by different neurosurgeons, who might have used different techniques, causing bias. ${ }^{1,4}$

Third, the study may be statistically underpowered, since results were evaluated in only 21 cases. Additionally, loss to follow-up was not reported.

Fourth, they used only one simple scale (graduated $0-4)$ for the 5-item questionnaire and the VAS for overall patient satisfaction. We think that these measures are insufficient to evaluate clinical, functional, and aesthetic outcomes of 2 different approaches..$^{10}$ Indeed, for more ap- propriate evaluation it would also be necessary to include other measures of outcome, such as quantitative radiological measures (percentage reduction in thickness and volumetric images), temporal muscle analysis, and functional outcomes (e.g., modified Rankin Scale or Oswestry Disability Index), at specific follow-up times. In addition, further comparisons, including complications such as incidence of frontalis muscle palsy, postoperative hemorrhage, cerebrospinal fistula, hydrocephalus, and mortality, would be interesting. ${ }^{4,5}$

Research in minimally invasive approaches in neurosurgery has exponentially increased in the past decade, and technological developments have led to improvements in precision and effectiveness. ${ }^{6}$ Nevertheless, many senior neurosurgeons remain reluctant to change their clinical practice for less-invasive alternatives. Currently, there is great concern regarding the reduction of invasiveness to avoid the complications inherent to large exposures, but there is still controversy about whether these techniques afford satisfactory surgical exposure when compared with conventional craniotomies. ${ }^{7}$

The key point is to use the most adequate technique for a particular patient, rather than using a one-size-fits-all approach for all patients. Minimally invasive approaches are the new frontier in neurosurgery, and technological innovation and integration are crucial to ongoing progress in the application of these techniques. ${ }^{9}$ Research like this study by Park and colleagues is important to support the selection of minimally invasive procedures.

\section{Nícollas Nunes Rabelo, MD Bruno Braga Sisnando da Costa, MD Manoel Jacobsen Teixeira, MD, PhD Eberval Gadelha Figueiredo, MD, PhD University of São Paulo, São Paulo, Brazil}

\section{References}

1. Figueiredo EG, Deshmukh P, Nakaji P, Crusius MU, Crawford N, Spetzler RF, et al: The minipterional craniotomy: technical description and anatomic assessment. Neurosurgery 61 (5 Suppl 2):256-265, 2007

2. Figueiredo EG, Deshmukh V, Nakaji P, Deshmukh P, Crusius MU, Crawford N, et al: An anatomical evaluation of the mini-supraorbital approach and comparison with standard craniotomies. Neurosurgery 59 (4 Suppl 2): ONS212ONS220, 2006

3. Figueiredo EG, Deshmukh P, Nakaji P, Shu EB, Crawford N, Spetzler RF, et al: An anatomical analysis of the mini-mod- 
ified orbitozygomatic and supra-orbital approaches. J Clin Neurosci 19:1545-1550, 2012

4. Figueiredo EG, Deshmukh P, Zabramski JM, Preul MC, Crawford NR, Siwanuwatn R, et al: Quantitative anatomic study of three surgical approaches to the anterior communicating artery complex. Neurosurgery 56 (2 Suppl):397-405, 2005

5. Figueiredo EG, Deshmukh P, Zabramski JM, Preul MC, Crawford NR, Spetzler RF: The pterional-transsylvian approach: an analytical study. Neurosurgery 62 (6 Suppl 3):1361-1367, 2008

6. Mandel M, Petito CE, Tutihashi R, Paiva W, Abramovicz Mandel S, Gomes Pinto FC, et al: Smartphone-assisted minimally invasive neurosurgery. J Neurosurg [epub ahead of print March 13, 2018; DOI: 10.3171/2017.6.JNS1712]

7. Mandel M, Tutihashi R, Mandel SA, Teixeira MJ, Figueiredo EG: Minimally invasive transpalpebral 'eyelid" approach to unruptured middle cerebral artery aneurysms. Oper Neurosurg (Hagerstown) 13:453-464, 2017

8. Park J, Son W, Kwak Y, Ohk B: Pterional versus superciliary keyhole approach: direct comparison of approachrelated complaints and satisfaction in the same patient. J Neurosurg [epub ahead of print March 2, 2018; DOI: 10.3171/2017.8.JNS171167]

9. Siwanuwatn R, Deshmukh P, Figueiredo EG, Crawford NR, Spetzler RF, Preul MC: Quantitative analysis of the working area and angle of attack for the retrosigmoid, combined petrosal, and transcochlear approaches to the petroclival region. J Neurosurg 104:137-142, 2006

10. Welling LC, Figueiredo EG, Wen HT, Gomes MQ, BorSeng-Shu E, Casarolli C, et al: Prospective randomized study comparing clinical, functional, and aesthetic results of minipterional and classic pterional craniotomies. J Neurosurg 122:1012-1019, 2015

\section{Disclosures}

The authors report no conflict of interest.

\section{Correspondence}

Eberval Gadelha Figueiredo: ebgadelha@yahoo.com.

\section{INCLUDE WHEN CITING}

Published online August 24, 2018; DOI: 10.3171/2018.6.JNS181491.

\section{Response}

I really appreciate Rabelo and colleagues' thoughtful comments on our article and would like to provide the following responses.

Surgical minimalism to reduce iatrogenic traumatization is a universal trend in most surgical fields. Since the concept of a keyhole approach was first advocated by Perneczky and colleagues, ${ }^{10,12}$ a superciliary keyhole approach has been applied to many tumorous lesions in the parasellar region and anterior circulation aneurysms. However, superciliary keyhole surgery still raises major technical and cosmetic concerns. Indeed, the small cranial opening of a keyhole approach does create technical limitations. However, these limitations can be overcome by using appropriate surgical indications, slender surgical instruments, and optimized surgical techniques. . $^{13-5,7-9}$ Our previous surgical series including small unruptured aneurysms arising at the supraclinoid ICA, $\mathrm{A}_{1}, \mathrm{ACoA}, \mathrm{M}_{1}$, and MCA bifurcation revealed excellent surgical outcomes. In addition, keyhole surgery facilitates tremor-free procedures as the surgical instruments are supported by the margin of the small cranial opening.
While previous studies have already shown favorable cosmetic outcomes, ${ }^{2,6,9,11}$ the current study aimed to compare the cosmetic concerns and approach-related complaints of patients who underwent both superciliary and pterional approaches. Thus, despite the limitations of the current study, the results can help transition cosmetic and approach-related concerns into confidence.

\section{Jaechan Park, MD, PhD \\ Kyungpook National University, Daegu, Republic of Korea}

\section{References}

1. Choi YJ, Son W, Park KS, Park J: Intradural procedural time to assess technical difficulty of superciliary keyhole and pterional approaches for unruptured middle cerebral artery aneurysms. J Korean Neurosurg Soc 59:564-556, 2016

2. Goh DH, Kim GJ, Park J: Medpor craniotomy gap wedge designed to fill small bone defects along cranial bone flap. $\mathbf{J}$ Korean Neurosurg Soc 46:195-198, 2009

3. Park J: Clip-knotting technique for intracranial arterial suturing through deep and narrow surgical corridors-how I do it. Acta Neurochir (Wien) 157:769-771, 2015

4. Park J: Self-drilling anchor screws for dural tenting sutures: technical note. Surg Neurol 72:175-176, 2009

5. Park J: Superciliary keyhole approach for unruptured anterior circulation aneurysms: surgical technique, indications, and contraindications. J Korean Neurosurg Soc 56:371-374, 2014

6. Park J, Jung TD, Kang DH, Lee SH: Preoperative percutaneous mapping of the frontal branch of the facial nerve to assess the risk of frontalis muscle palsy after a supraorbital keyhole approach. J Neurosurg 118:1114-1119, 2013

7. Park J, Kang DH, Chun BY: Superciliary keyhole surgery for unruptured posterior communicating artery aneurysms with oculomotor nerve palsy: maximizing symptomatic resolution and minimizing surgical invasiveness. J Neurosurg 115:700-706, 2011

8. Park J, Son W, Goh DH, Kang DH, Lee J, Shin IH: Height of aneurysm neck and estimated extent of brain retraction: powerful predictors of olfactory dysfunction after surgery for unruptured anterior communicating artery aneurysms. J Neurosurg 124:720-725, 2016

9. Park J, Woo H, Kang DH, Sung JK, Kim Y: Superciliary keyhole approach for small unruptured aneurysms in anterior cerebral circulation. Neurosurgery 68 (2 Suppl Operative):300-309, 2011

10. Reisch R, Perneczky A: Ten-year experience with the supraorbital subfrontal approach through an eyebrow skin incision. Neurosurgery 57 (4 Suppl):242-255, 2005

11. Shin D, Park J: Unruptured supraclinoid internal carotid artery aneurysm surgery: superciliary keyhole approach versus pterional approach. J Korean Neurosurg Soc 52:306-311, 2012

12. van Lindert E, Perneczky A, Fries G, Pierangeli E: The supraorbital keyhole approach to supratentorial aneurysms: concept and technique. Surg Neurol 49:481-490, 1998

INCLUDE WHEN CITING

Published online August 24, 2018; DOI: 10.3171/2018.7.JNS181714.

CAANS 2019, except where prohibited by US copyright law

\section{Multiple sclerosis-related tremor and stereotactic radiosurgery}

TO THE EDITOR: We read with interest the article 
by Raju et al. ${ }^{8}$ on stereotactic radiosurgery for medically refractory multiple sclerosis tremor (Raju SS, Niranjan A, Monaco EA III, et al: Sterotactic radiosurgery for medically refractory multiple sclerosis-related tremor. $\mathrm{J} \mathrm{Neu}$ rosurg 128:1214-1221, April 2018).

Historically, this neurosurgery was first described and performed by Spiegel and Wycis, ${ }^{10,11}$ followed by Narabayashi, ${ }^{6}$ Obrador, ${ }^{7}$ Riechert, ${ }^{9}$ and others, with satisfactory result. During the "down time" for functional stereotaxy, progress was being made in diagnosis and anatomical localization using CT and MRI., ${ }^{1,3}$ In the spring of 1985 , my colleague Dr. Hill and I conferred with Dr. Latchaw at Pittsburgh Medical Center over thalamic and subthalamic localization $^{5,12}$ for a patient with bilateral multiple sclerosis (MS), but who was most symptomatic in her dominant left brain for the right hand. In August 1985, a lesion with CT localization for a target in the left subthalamus as well as the ventrolateral thalamus was treated through a single burr hole. In both loci, the electrode was first passed to the left subthalamus for a radiofrequency (RF) lesion, and then withdrawn to the left thalamus to make the second RF lesion. There was MRI conformation of both loci. An excellent result was achieved. The right brain lesion clinically worsened. In the spring of 1986 a single, rightthalamic ventrolateral RF lesion was placed with poor result. A week later with re-imaging a single more lateral, superior, and posterior RF lesion was made with excellent result, and MRI confirmation. The patient's neurological result remained good/excellent under my observation for the next nearly 5 years. This clinical case was published in Applied Neurophysiolog $y^{2}$ by Dr. Gildenberg, the editor of the journal and my fellow resident at Temple Medicine; with the passing of Dr. Spiegel, Confinia Neurologica stopped publication. The above authors have done a very good job in helping these MS patients with this variable clinical and neuropathological affliction.

Richard Lehman, MD Kiawah Island, SC

Richard P. Hill, MD Osage Beach, MO

\section{References}

1. Latchaw RE, Lunsford LD, Kennedy WH: Reformatted imaging to define intercommissural line for CT-guided stereotaxic functional neurosurgery. AJNR Am J Neuroradiol 6:429-433, 1985

2. Lehman RM, Hill RP: Computed-tomography-directed stereotaxis for movement disorder with postoperative magnetic resonance imaging conformation. Appl Neurophysiol 51:21-28, 1988

3. Leksell L, Herner T, Leksell D, Persson B, Lindquist: Visualization of stereotactic radiolesions by nuclear magnetic resonance. J Neurol Neurosurg Psychiatry 48:19-20, 1985

4. Lunsford LD: Stereotaxy and the role of CT in morphological and functional surgery of the human brain, in Latchaw RE (ed): Computed Tomography of the Head, Neck and Spine. Chicago: Yearbook, 1985, pp 743-764

5. Maxwell RE, Mollman HD, Lund G: Magnetic resonance directed stereotax is in functional neurosurgery and neurooncology, in 55th AANS Annual Meeting. Rolling Meadows, IL: AANS, 1987
6. Narabayashi H: Functional differentiation in and around the ventrolateral nucleus of the thalamus based on experience in human stereoencephalotomy. Johns Hopkins Med J 122:295-300, 1968

7. Obrador S, Dierssen G: Observations on the treatment of intentional and postural tremor by subcortical stereotaxic lesions. Confin Neurol 26:250-253, 1965

8. Raju SS, Niranjan A, Monaco EA III, Flickinger JC, Lunsford LD: Stereotactic radiosurgery for medically refractory multiple sclerosis-related tremor. J Neurosurg 128:12141221, 2018

9. Riechert T: Stereotactic Brain Operations: Methods, Clinical Aspects, Indications. Bern: Huber, 1980

10. Spiegel EA, Wycis HT: Stereoencephalotomy. Thalamotomy and Related Procedures. Part I. Methods and Stereotaxic Atlas of the Human Brain. New York: Grune \& Stratton, 1952

11. Spiegel EA, Wycis HT: Stereoencephalotomy. Part II. Clinical and Physiological Applications. New York: Grune \& Stratton, 1962

12. Wyper DJ, Turner JW, Patterson J, Condon BR, Grossart KWM, Jenkins A, et al: Accuracy of stereotactic localization using MRI and CT. J Neurol Neurosurg Psychiatry 49:1445-1448, 1986

\section{Disclosures}

The authors report no conflict of interest.

\section{Correspondence}

Richard Lehman: richard.lehman5@comcast.net.

\section{INCLUDE WHEN CITING}

Published online October 19, 2018; DOI: 10.3171/2018.7.JNS182088.

\section{Response}

We thank Drs. Lehman and Hill for their interest in our work. We greatly appreciated the historical vignette they provided. We also read with interest their initial personal experience with thalamic lesioning for a patient with MS-related tremor in 1985 and 5 years of follow-up. Drs. Lehman and Hill thoughtfully reference some of our early work from 33 years ago using CT to perform functional neurosurgery. In that era preceding MRI, many were resistant to using CT to target deep brain structures, relying even then on air or contrast encephalography to define standard stereotactic landmarks such as the anterior and posterior commissures. The advent and maturation of MRI finally gave us the means to better define these landmarks, as well as the internal capsule. Advanced MRI now allows us to perform thalamic segmentation and tractography in each patient preoperatively. We thank them for their encouraging comments.

$$
\begin{array}{r}
\text { Ajay Niranjan, MD, MBA } \\
\text { L. Dade Lunsford, MD } \\
\text { University of Pittsburgh Medical Center, Pittsburgh, PA } \\
\text { Sudesh S. Raju, BA } \\
\text { University of Pittsburgh School of Medicine, Pittsburgh, PA }
\end{array}
$$

INCLUDE WHEN CITING

Published online October 19, 2018; DOI: 10.3171/2018.8.JNS182146.

CAANS 2019, except where prohibited by US copyright law 


\section{Activity versus injury: further defining the risk/benefit ratio in the Neurosurgery Charity Softball Tournament}

TO THE EDITOR: We read with great interest the Letter to the Editor by Taylor et al. ${ }^{5}$ (Taylor DG, Buell TJ, Wang TR, et al: Injury among neurosurgeons participating in organized softball. J Neurosurg 129:844-845, September 2018) responding to the 15 th anniversary commemorative article by Komotar et al. ${ }^{1}$ detailing the creation, development, and establishment of the Annual Neurosurgery Charity Softball Tournament (Komotar RJ, Goldstein HE, Bruce JN: The Annual Neurosurgery Charity Softball Tournament: 15th Anniversary Commemorative Article. The creation, development, and establishment of a neurosurgical tradition. J Neurosurg 128:1605-1611, June 2018). Taylor and colleagues refer to a remarkable incidence of injuries, musculoskeletal in particular, among the University of Virginia (UVA) neurosurgery softball team members. In a brief 3-year period of play, an injury rate of $36.8 \%$ among the softball participants occurred by year 1 , and almost half of the players were injured by 2.5 years, for a total of 9 injuries. A higher rate was noted among residents as opposed to faculty.

In contradistinction, the University of Miami (UM) team, which has been involved in the tournament for the last 10 years, has had only 2 minor hamstring injuries that resulted in players being pulled early from a game, none requiring further medical attention. There was a clear difference in the overall injury incidence rate during the actual tournament between UVA and UM, and the UVA rate should not be felt to reflect the national trend. It should also be noted that the UM's Tourney experience has extended well into the deeper portions of the tournament, so the potential exposure to injury is much higher than the typical 3 games and out by UVA. Emotional injuries in close losses and veisalgia (severe hangover) should not be counted in sporting injury stats. There have certainly been some additional minor soft-tissue injuries without fractures during the 3-4 months' training period that preceded the tournament. One needs to emphasize that preTourney team training and practice, along with hydration and stretching during the game, form a major strategy in injury prevention.

Softball is one of the few team sports that participants can compete in during one's "later" years. In reviewing statistics published from the US national health report, ${ }^{4}$ we found that softball injury rates account for only $4.7 \%$ of annual injury episodes among sporting and recreational activities. This incidence rate supports the assertion that injury metrics in softball fall well below those of other potential sporting activities, and softball has the added benefit of team-based sports. I (A.D.L.) can attest to the danger of other sports injuries, including those incurred while cycling and skiing at 7 and 10 weeks, respectively, prior to the tournament (Fig. 1).

Our neurosurgical specialty is fraught with long pe-
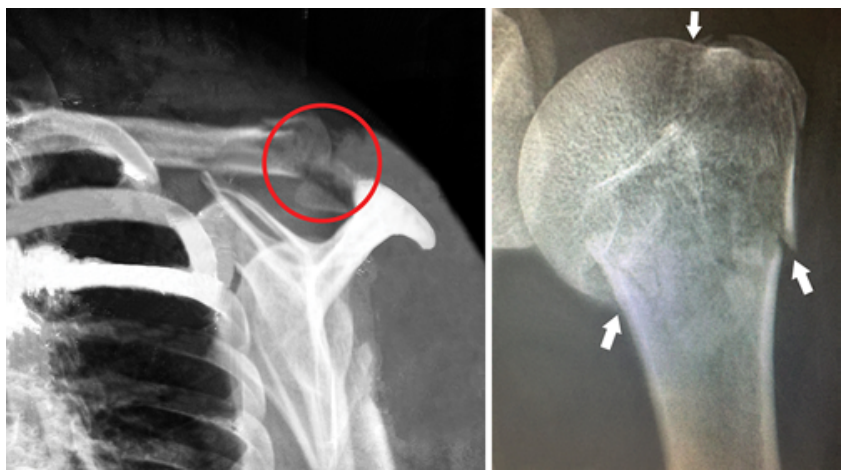

FIG. 1. Left: Left distal clavicular fracture incurred from cycling. Right: Left proximal humeral fractures from skiing. Figure is available in color online only.

riods of non-activity, standing/sitting, or at best walking around the hospital halls. Neurosurgery resident and faculty "burnout" is increasingly recognized as an important stressor in our specialty and can ultimately result in a decline in a physician's personal, physical, and mental well-being. ${ }^{2,3}$ Having neurosurgical faculty members and residents interact as a softball team, a venue much different from our usual medical settings, has great value for our specialty in an era of increasing bureaucracy and regimentation. Involvement in the Tourney is a natural physical outlet for faculty and residents to exercise, train, and participate in a team sport that promotes well-being and camaraderie, two well-recognized measures to counteract stress and prevent burnout. When we tell our nonneurosurgical colleagues about the Tourney, they are astonished that we have the camaraderie and organization skills to do it year after year. It is one of the things that makes neurosurgery unique.

Although both local and national statistics demonstrate that the risks of participation are low, the game and tournament are not zero-risk endeavors. We must emphasize that we are a family, and we must as a family of neurosurgeons do everything we can to reduce the risk of injury to each other during these tournaments. This includes taking a serious look at attitudes or instincts that are considered dangerous, such as aggressive running into a catcher at home plate, the use of metal cleats, and the use of bats that can lead to accelerated softball velocities, potentially resulting in player injuries. We must participate in this tournament in the spirit of friendly competition, not a "win at any price" attitude. Actions such as those mentioned above have no place in this tournament.

I would like to congratulate Drs. Komotar and Bruce for initiating this tournament within our field and making it one of the most well-recognized and well-attended neurosurgical meetings in our specialty.

Allan D. Levi, MD, PhD

Robert M. Starke, MD

Ricardo J. Komotar, MD

University of Miami Miller School of Medicine, Miami, FL

Robert E. Harbaugh, MD

Penn State University, Milton S. Hershey Medical Center, Hershey, PA 


\section{References}

1. Komotar RJ, Goldstein HE, Bruce JN: The Annual Neurosurgery Charity Softball Tournament: 15th Anniversary Commemorative Article. The creation, development, and establishment of a neurosurgical tradition. J Neurosurg 128:1605-1611, 2018

2. McAbee JH, Ragel BT, McCartney S, Jones GM, Michael LM II, DeCuypere M, et al: Factors associated with career satisfaction and burnout among US neurosurgeons: results of a nationwide survey. J Neurosurg 123:161-173, 2015

3. Shakir HJ, McPheeters MJ, Shallwani H, Pittari JE, Reynolds RM: The prevalence of burnout among US neurosurgery residents. Neurosurgery 83:582-590, 2018

4. Sheu Y, Chen LH, Hedegaard H: Sports- and recreationrelated injury episodes in the United States, 2011-2014. Natl Health Stat Report 99:1-12, 2016

5. Taylor DG, Buell TJ, Wang TR, Sheppard MJ, Maggio D, Chen CJ, et al: Injury among neurosurgeons participating in organized softball. J Neurosurg 129:844-845, 2018 (Letter)

\section{Disclosures}

Dr. Levi receives teaching honorarium from the American Association of Neurological Surgeons and grant support from the Department of Defense.

\section{Correspondence}

Allan D. Levi: alevi@med.miami.edu.

\section{INCLUDE WHEN CITING}

Published online October 26, 2018; DOI: 10.3171/2018.8.JNS182102.

\section{Response}

No response was received from the authors of the original article.

\section{INCLUDE WHEN CITING}

Published online Month Day, 2018; DOI: 10.3171/.

CAANS 2019, except where prohibited by US copyright law

\section{Prognostication in traumatic brain injury}

TO THE EDITOR: The ability to predict the outcome after traumatic brain injury (TBI) adds to the clinical armamentarium of everyone involved in the care of such patients. This ability helps not only in planning better and more aggressive care of those patients with predicted borderline prognosis, but also in preparing the patient's family in cases with grave prognosis. I read with interest the articles by Brennan et al. ${ }^{1}$ and Murray et al. ${ }^{2}$ (Brennan PM, Murray GD, Teasdale GM: Simplifying the use of prognostic information in traumatic brain injury. Part 1: The GCS-Pupils score: an extended index of clinical severity. $J$ Neurosurg 128:1612-1620, June 2018; Murray GD, Brennan PM, Teasdale GM: Simplifying the use of prognostic information in traumatic brain injury. Part 2: Graphical presentation of probabilities. J Neurosurg 128:1621-1634, June 2018).

In part 1, the authors modified the existing Glasgow Coma Scale (GCS) to improve the assessment of the severity of TBI. The pupillary reactivity to light is one of the most significant prognostic factors, next to only age and conscious level at admission. The addition of pupillary response to the GCS score will definitely improve the assessment of severity of TBI, and GCS-Pupils (GCS-P) score will be an important prognostic factor. The GCS-P score is definitely going to be used widely in the future. The original GCS score is a very easy-to-use bedside tool with a minimum interobserver variability. The impact of the addition of pupil score on interobserver variability remains to be determined.

In part 2, the authors included age, CT scan findings, and GCS-P; tried to formulate a prognostic model; and compared the results with the CRASH (Corticosteroid Randomization After Significant Head Injury) and IMPACT (International Mission for Prognosis and Clinical Trials in Traumatic Brain Injury) models. The authors found that the prognostication by all these models was comparable. This model probably needs to be simplified to avoid complex charts and grids for easy bedside application.

Some of the multivariate prognostic models are currently available in computer-based and mobile-based apps for easy use. One such model is the Madras Head Injury Prognostic Scale (MHIPS) introduced by the author. ${ }^{3}$ This model is based on six easily available bedside prognostic factors: age, motor response, pupillary reaction, oculocephalic response, CT scan findings, and other systemic injuries graded on a numeric scale similar to the GCS. The MHIPS is very easy to apply at the bedside and has a very high predictive value, as proved by both internal and external validation. ${ }^{3}$ It is available on a computer-based app (www.medicalalgorithms.com) and mobile app ("Medal") for easy day-to-day application. The CRASH and IMPACT models are also available on computer-based apps. The proposed prognostic model including the GCS-P probably needs to be modified as an app (avoiding complex grids and charts) for easy application.

\section{Vengalathur Ganesan Ramesh, MCh, FRCS Chettinad Hospital \& Research Institute, Chettinad Academy of Research \& Education, Chennai, Tamilnadu, India}

\section{References}

1. Brennan PM, Murray GD, Teasdale GM: Simplifying the use of prognostic information in traumatic brain injury. Part 1: The GCS-Pupils score: an extended index of clinical severity. J Neurosurg 128:1612-1620, 2018

2. Murray GD, Brennan PM, Teasdale GM: Simplifying the use of prognostic information in traumatic brain injury. Part 2: Graphical presentation of probabilities. J Neurosurg 128:1621-1634, 2018

3. Ramesh VG, Thirumaran KP, Raja MC: A new scale for prognostication in head injury. J Clin Neurosci 15:11101114,2008

\section{Disclosures}

The author reports no conflict of interest.

\section{Correspondence}

Vengalathur Ganesan Ramesh: drvgramesh@hotmail.com.

\section{INCLUDE WHEN CITING}

Published online November 2, 2018; DOI: 10.3171/2018.7.JNS182128. 


\section{Response}

We thank Dr. Ramesh for his comments. We would like to clarify that the GCS-P is not adding new prognostic information to multivariate models. Instead it is a new, simple way of handling the combined effects of the GCS score and pupil reactivity without the need to make a calculation in a more complex model. In the pooled data for mortality, the $\mathrm{R}^{2}$ (a measure of the proportion of variability in outcome that is explained by the logistic regression model) for more complex models ranged from $22.7 \%$ to $23.2 \%$ and for the GCS-P ranged from $21.1 \%$ to $22.6 \%$.

There are many well-developed prognostic models in TBI, all with broadly comparable performance, none of which are widely used in practice. We are fundamentally presenting a new means of implementation (charts) rather than yet another model. The very limited information available on the MHIPS indicates that neither its predictive performance nor its practical uptake is an improvement on existing methods.

We are disappointed that the author found the charts themselves complex. The charts present the effects of 3 features and their interactions with a clarity and transparency not achieved by production of a set of probabilities from multivariate modelling.

Paul M. Brennan, MBBChir, FRCS, PhD Centre for Clinical Brain Sciences, University of Edinburgh, United Kingdom

Gordon D. Murray, MA, PhD Usher Institute of Population Health Sciences and Informatics, University of Edinburgh, United Kingdom

Graham M. Teasdale, MBBS, FRCP, FRCS Institute of Health and Wellbeing, University of Glasgow, United Kingdom

\section{INCLUDE WHEN CITING}

Published online November 2, 2018; DOI: 10.3171/2018.8.JNS182159.

CAANS 2019, except where prohibited by US copyright law

\section{Pure arterial malformation: a rare vascular entity}

TO THE EDITOR: We read with great interest the article by Brinjikji and colleagues ${ }^{1}$ (Brinjikji W, Cloft HJ, Flemming KD, et al: Pure arterial malformations. J Neurosurg 129:91-99, July 2018). The authors presented a consecutive series of 12 patients meeting criteria for a pure arterial malformation (PAM). First described in 2013 by McLaughlin et al., ${ }^{2}$ these malformations have been defined as vascular lesions with dilated, overlapping, and tortuous arteries, with no venous component or arteriovenous shunting. Pure arterial malformations are thought to have a pathophysiology and natural history different from that of more commonly diagnosed vascular lesions, including dolichoectasia, vascular malformation, and aneurysm. In the case series presented, 4 lesions had focal aneurysms associated with the lesion, with no disability, stroke, or hemorrhage at the median 29-month follow-up. Given the low rates of complications, the authors concluded that these lesions probably have a benign natural history.

We highly commend the authors' effort in presenting such a rare vascular entity and a summary of case reports existing in the literature. While we agree that there is much-needed effort into understanding this phenomenon, we remain cautious against concluding that these lesions are benign and, herein, present 2 cases from our institution with radiographic appearances similar to those of pure arterial malformations but with hemorrhage and requiring subsequent treatment.

In one case, a 45-year-old woman presented with subarachnoid hemorrhage (SAH). On digital subtraction angiography (DSA), the patient was found to have a dilated tortuous vessel at the posterior cerebral artery (PCA), which looked remarkably similar to a pure arterial malformation (Fig. 1A). The patient underwent clipping of the aneurysm, and the pathology demonstrated myxoid degeneration and focal dissection at the aneurysmal dome site (Fig. 1B).

We also previously published a case report ${ }^{3}$ of a double-origin posterior inferior cerebellar artery (PICA) aneurysm in a 42-year-old woman with SAH in the posterior fossa on CT scanning. DSA was performed (Fig. 1C), with similar dilated tortuosity to a pure arterial malformation, but on surgical dissection, it was confirmed to be an aneurysm. The patient was treated by trapping of the aneurysm, resection, and end-to-end anastomosis of the PICA limbs.

In the authors' literature review, 2 cases presented with radiographic infarction and hemorrhage thought to be as-

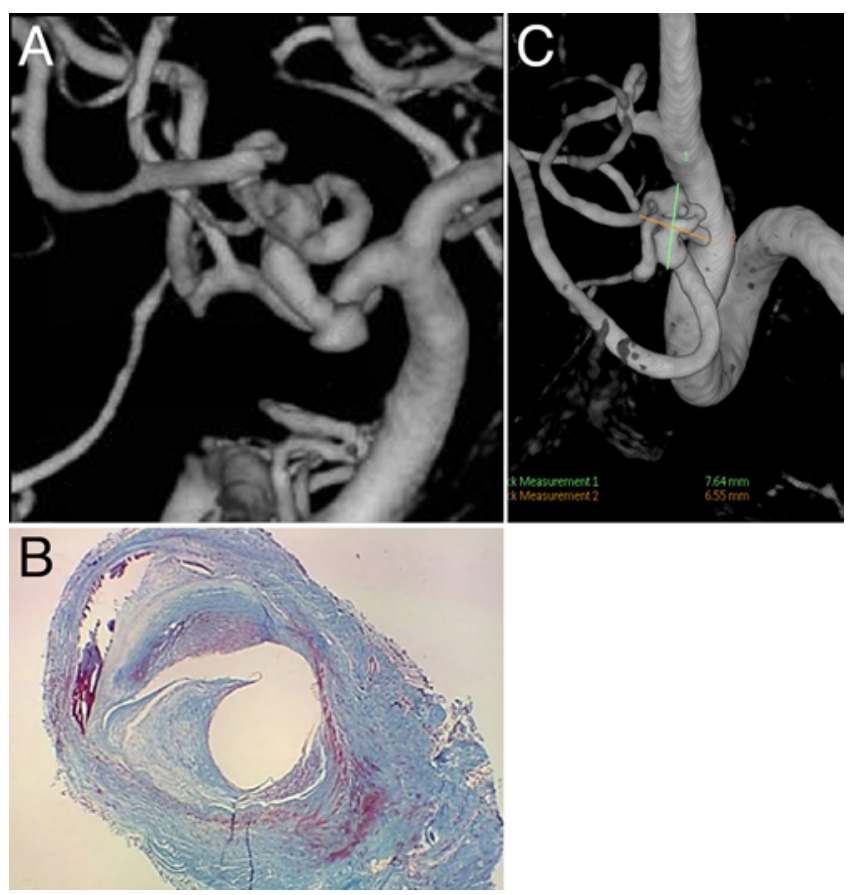

FIG. 1. A 45-year-old woman presented with $\mathrm{SAH}$ and a dilated tortuous vessel at the PCA $(\mathbf{A})$, with pathology demonstrating myxoid degeneration and focal dissection at the aneurysm dome site (B). Another case of a 42-year-old woman who presented with similar dilated tortuosity at the PICA to a pure arterial malformation, but on surgical dissection, it was confirmed to be an aneurysm (C). Figure is available in color online only. 
sociated with lenticulostriate aneurysm rupture. Here, we present 2 cases with radiographic similarities to pure arterial malformations on DSA, with dilated tortuous vessels but no evidence of venous shunting. However, both cases presented with symptomatic SAH and with confirmed aneurysm rupture in surgery. As the authors proposed a possible etiology of pure arterial malformations as chronic dissecting aneurysms, we wonder how to best characterize these lesions and differentiate them from a dissecting aneurysm or other types of malformations that may carry a nonbenign course.

We agree that the evaluation of clinical and natural history of these rare entities is important in order to distinguish these lesions from arteriovenous malformations and dissecting aneurysms, but we wanted to highlight that we have found it difficult to identify and differentiate these lesions in our practice and would remain cautious from concluding their benign course until longer follow-up and additional cases in the literature are identified.

\section{Pui Man Rosalind Lai, MD \\ Nirav J. Patel, MD \\ Brigham and Women's Hospital and Harvard Medical School, Boston, MA}

\section{References}

1. Brinjikji W, Cloft HJ, Flemming KD, Comelli S, Lanzino G: Pure arterial malformations. J Neurosurg 129:91-99, 2018

2. McLaughlin N, Raychev R, Duckwiler G, Martin NA: Pure arterial malformation of the posterior cerebral artery: importance of its recognition. J Neurosurg 119:655-660, 2013

3. Silva MA, See AP, Aziz-Sultan MA, Patel NJ: surgical treatment of a double origin posterior inferior cerebellar artery aneurysm and insights from embryology: case report and literature review. Oper Neurosurg (Hagerstown) 13:E8-E12, 2017

\section{Disclosures}

The authors report no conflict of interest.

\section{Correspondence}

Nirav J. Patel: npate140@bwh.harvard.edu.

\section{INCLUDE WHEN CITING}

Published online November 16, 2018; DOI: 10.3171/2018.8.JNS182423.

\section{Response}

We would like to thank Drs. Lai and Patel for their interest in our article on pure arterial malformations. ${ }^{1}$ The authors present 2 interesting cases of lesions that resembled pure arterial malformations but presented with SAH. We do not believe that the lesions described in the letter were pure arterial malformations but, rather, acutely ruptured dissecting aneurysms.
It is important to point out that in our article on pure arterial malformations, all the lesions that we identified were incidental and completely asymptomatic. We have identified several additional cases since our article's publication and they too were incidental asymptomatic lesions and were found to have a benign natural history both clinically and on imaging.

We do not dispute the notion that acute ruptured dissecting aneurysms can have a similar angiographic appearance to pure arterial malformations, as we suspect that many pure arterial malformations are chronic healed dissections that occurred early in life but were asymptomatic. We recently identified a PICA pure arterial malformation that occurred in an extra-axial lipoma, which suggests that this particular lesion was congenital. ${ }^{3}$ Many of the cases in our series had calcifications, suggesting that they were long-standing lesions.

We agree with the authors that longer follow-up and additional cases in the literature are needed in order for us to be sure about the natural history of these lesions. However, uncertainty regarding a lesion's natural history should not necessarily prompt aggressive surgical or endovascular treatment, especially for lesions with angioarchitecture as complex as some of the pure arterial malformations seen in our series.

Lastly, we would have loved to have seen additional images from the authors' presented cases, including the noncontrast CT showing the SAH and perhaps a 2D DSA in a working projection to show the angioarchitecture of the PCA and PICA lesions. Based on the images provided, the lesions appear to more closely resemble dysplastic dissecting aneurysms than the dilated overlapping and tortuous arteries seen with pure arterial malformations. ${ }^{2}$

\section{Waleed Brinjikji, MD} Giuseppe Lanzino, MD Mayo Clinic, Rochester, MN

\section{References}

1. Brinjikji W, Cloft HJ, Flemming KD, Comelli S, Lanzino G: Pure arterial malformations. J Neurosurg 129:91-99, 2018

2. McLaughlin N, Raychev R, Duckwiler G, Martin NA: Pure arterial malformation of the posterior cerebral artery: importance of its recognition. J Neurosurg 119:655-660, 2013

3. Sorenson TJ, Brinjikji W, Flemming KD, Lanzino G: Pure arterial malformation of the posterior inferior cerebellar artery with interspersed adipose tissue: case report. J Neurosurg Pediatr 22:261-264, 2018

\section{INCLUDE WHEN CITING}

Published online November 16, 2018; DOI: 10.3171/2018.9.JNS182479.

CAANS 2019, except where prohibited by US copyright law 